\title{
LOHENSTEINS »ARMINIUS»
}

Disputatorisches Verfahren und Lehrgehalt in einem Roman ZWISCHEN BAROCK UND AUFKLÄRUNG

\author{
INAUGURAL-DISSERTATION \\ zur Erlangung der Doktorwürde der \\ Philosophischen Fakultät \\ der \\ Johannes Gutenberg-Universität zu Mainz
}

\author{
vorgelegt von \\ Dieter Kafitz \\ aus Saarbrücken
}

Stuttgart

1970 
Referent: Professor Dr. F.-W. Wentzlaff-Eggebert

1. Korreferent: Professor Dr. H.-H. Krummacher

2. Korreferent: Professor Dr. G. Funke

Tag der mündlichen Prüfung: 14. Mai 1969

ISBN 978-3-476-99676-3 ISBN 978-3-476-99675-6 (eBook)

DOI 10.1007/978-3-476-99675-6

Die vorliegende Arbeit erscheint gleichzeitig in den

"Germanistischen Abhandlungen"

der J. B. Metzlerschen Verlagsbuchhandlung Stuttgart 


\section{INHALT}

EINLEITUNG . . . . . . . . . . . . . . . . . . . . . 1

A. EINFÜHRUNG IN DEN »ARMINIUS «-ROMAN . . . . . . . . . . . . . . 12

I. Deskriptiv-systematische Einführung . . . . . . . . . . . . 12

II. Die zeitgenössischen Arminius-Rezensionen . . . . . . . . . . . . . . . 26

a) Deutsche Romanpoetik im 17. und frühen 18. Jahrhundert . . . . . . . 26

b) Die Arminius-Kritiker der Frühaufklärung (Christian Thomasius, HunoldMenantes, Christian Gebauer) . . . . . . . . . . . 35

c) Die barocken Lobredner des Arminius (Acta Eruditorum, Tentzel, Schröter, Männling) . . . . . . . . . . . . . . 45

d) Gegner des Arminius (Gotthard Heidegger) . . . . . . . . . . . 49

B. Das disputatorische Verfahren . . . . . . . . . . . . . . . . . 54

I. Die Gespräche im Arminius . . . . . . . . . . . . . . . . . 54

II. Urteilsenthaltung der Romanfiguren . . . . . . . . . . . . . . . . . . 61

III. Skeptizismus und Eklektizismus . . . . . . . . . . . . . . . 71

IV. Cartesianismus . . . . . . . . . . . . . 80

C. Der Lehrgehalt Des "ARMiniUs « . . . . . . . . . . . . . . . . . . . . 91

I. Bedingtheit und Möglichkeit der Vernunft . . . . . . . . . . . . . . . . 91

a) Erkenntnisoptimismus und Fortschrittsglaube . . . . . . . . . 91

b) Vernunft und Glaube . . . . . . . . . . . . . . . . . . . 96

c) Vernunftausbildung . . . . . . . . . . . . . . . . . . 99

d) Vernunftreiheit und Notwendigkeit . . . . . . . . . . . 103

II. "Vernünftiger Vernunftgebrauch" . . . . . . . . . . . . . 116

a) Praktische Weisheit . . . . . . . . . . . . . 116

b) Politische Klugheit . . . . . . . . . . . . . . . . . . . . 120

c) Soziale Weisheit . . . . . . . . . . . . . . . . . . . . . . . . 124

d) Unasketische Weisheit . . . . . . . . . . . . . . . 126 
Inhalt

III. Die tugendhafte Lebensführung . . . . . . . . . . . . . . . 129

a) Das »Mittel=Maaß « als »der Mäßstab aller Vollkommenheiten« . . . . . 129

b) Das maßvolle Wohlleben . . . . . . . . . . . . . . . 133

c) Die vernünftige Liebe . . . . . . . . . . . . . . . . . . 137

d) Die gemäßigten Leidenschaften . . . . . . . . . . . . . . . 140

e) Die diesseitsorientierte Standhaftigkeit . . . . . . . . . . . . . . . 147

f) Konstruktiver Eigennutz . . . . . . . . . . . . . . . . . . . . 151

IV. Die politische Lehre im Arminius . . . . . . . . . . . . 155

a) Die beste Staatsform . . . . . . . . . . . . . . . . 155

b) Das Widerstandsrecht . . . . . . . . . . . . . 160

c) Kirche und Staat . . . . . . . . . . . . . . . . . 164

d) Der ideale Herrscher . . . . . . . . . . . . . . 170

ExkURs . . . . . . . . . . . . . . . . . . 177

Lohensteins späte Trauerspiele Sophonisbe und Cleopatra vor dem Hintergrund des Arminius . . . . . . . . . . . . . . . . . 177

LITERATURVERZEICHNIS . . . . . . . . . . . . . . . . . . . . 199 